Article

\title{
Firefighting in Vulnerable Areas Based on the Connection between Fire Hydrants and Fire Brigade
}

\author{
Yoon Ha Lee ${ }^{1}$, Min Seok Kim ${ }^{2}$ (D) and Ji Soo Lee ${ }^{3, *}$ \\ 1 Innovative Durable Building and Infrastructure Research Center, Hanyang University, Ansan 15588, Korea; \\ dldbsgk123@naver.com \\ 2 School of Architecture, Civil, Environmental and Energy Engineering, Kyungpook National University, \\ Daegu 41566, Korea; kms910601@gmail.com \\ 3 Department of Fire Safety, Kyungil University, Gyeongsan 38428, Korea \\ * Correspondence: jisoo@kiu.kr; Tel.: +82-53-600-5416
}

check for

updates

Citation: Lee, Y.H.; Kim, M.S.; Lee, J.S. Firefighting in Vulnerable Areas Based on the Connection between Fire Hydrants and Fire Brigade. Sustainability 2021, 13, 98. https://dx.doi.org/10. 3390/su13010098

Received: 13 November 2020 Accepted: 21 December 2020 Published: 24 December 2020

Publisher's Note: MDPI stays neutral with regard to jurisdictional claims in published maps and institutional affiliations.

Copyright: () 2020 by the authors. Licensee MDPI, Basel, Switzerland. This article is an open access article distributed under the terms and conditions of the Creative Commons Attribution (CC BY) license (https: / / creativecommons.org / licenses/by/4.0/).

\begin{abstract}
A sufficient supply of water for firefighting is critical for effective responses to urban fires, thus reducing fire hazards. The aim of this study was the development of an analysis method for vulnerable areas with respect to firefighting activities that require the use of fire hydrants. In particular, a method was proposed for the determination of the operational range of firefighting activities based on the distribution of the fire hydrants and the roads that allow for the passage of firefighting vehicles. The proposed method, which employs a geographic information system (GIS), was applied to Buk-gu, Daegu City, South Korea. The research results revealed that the operational range of firefighting activities and vulnerable areas can be determined by studying the connection between the fire hydrant locations and the fire brigade in the analysis of the accessible areas. This study contributes to the development of GIS analysis methods for comprehensive vulnerability analyses of firefighting activities, including accessibility to fire hydrants.
\end{abstract}

Keywords: fire hydrant; fire brigade; geographic information system; vulnerable areas

\section{Introduction}

Fire incidents cause huge casualties and property damage every year. When a building is attacked by a fire, it not only has a direct negative impact on the sustainability of the building, but also affects the broader environment and community. Therefore, efficiently and effectively addressing the risks associated with building fire incidents is important [1]

Further to this, insufficient supply of water significantly increases the difficulties associated with firefighting activities, which poses an additional threat to life and property [2]. For example, a large fire that occurred in Shenzhen, Guangming District Rong Jian market (in December 2013) resulted in considerable human casualties and property damage because the water pressure of the fire hydrants was not sufficiently high, or the water quantity was not sufficient [2]. Kahanji et al. [3] analysed the causes and diffusion factors of a large fire that occurred in Cape Town, South Africa (March 2017), and it was found that the efforts of firefighters to extinguish the fire were interrupted by various factors, such as narrow access roads, lack of sufficient water supply in the area, and community interactions within specific areas. Considering these cases, high-capacity hydrants are critical for the reduction of fire hazards. Continuous management and systematic utilisation plans are required for the functioning of fire hydrants to be simple and for them to be fully utilised in the event of a fire. Therefore, fire hydrants were considered in studies for the evaluation of regional fire risks or the capacity of fire stations, e.g., [4-8].

A limited number of studies were conducted on accessibility to fire hydrants. However, spatial accessibility to fire stations has attracted significant research attention. In many previous studies on spatial accessibility to fire stations, e.g., [6,9-12], network analyses were conducted using a geographic information system (GIS). In these studies, service 
areas were determined, and the optimal regional allocations were analysed by setting the impedance cut-off distance or time. The analysis results considered the operation of actual firefighting vehicles because they reflect regional road networks. Therefore, in this study, an attempt was made to analyse the accessibility to fire hydrants based on a network analysis using a GIS.

In general, accessibility includes both regional proximity and regional availability [13]. Regional availability can be considered as the ratio of supply-demand for each demand location within a given threshold, and regional proximity accounts for the spatial interactions between the supply and demand sides [13]. Raškauskaitė and Grigonis [14] analysed the regional proximity and regional availability of fire hydrants using the GIS buffer tool. However, the operation of firefighting vehicles was excluded because road environments were not considered, similar to the study conducted by Wielebski and Medyńska-Gulij [15]. In previous studies, the range within which fire hydrants can be used was analysed based on the fire hydrant location. At the actual firefighting sites, the fire brigade is equipped with firefighting pumpers and tankers, and fire hydrants are secondary facilities for the supply of firefighting water. Therefore, the fire brigade location should be considered for the analysis of the operational range of actual firefighting activities. Moreover, narrow alleys through which fire engines cannot pass result in delayed firefighting operations and rescue, thereby causing considerable human casualties and property damage [16,17]. Therefore, in this study, an analysis method for the operational range of firefighting activities in vulnerable areas was proposed with respect to the fire hydrant location, fire brigade operation, and road width. The proposed method was applied to an urban area in South Korea, and a discussion is presented on its applicability and scope of future development.

\section{Materials and Methods}

Vulnerabilities can be defined as the potential for system corruption or change due to predetermined failures [18]. This concept of vulnerability is a dynamic one that depends on a disturbance's impacts and effects [18]. In this respect, a method was developed that mainly considers three aspects for the analysis of the vulnerable areas with respect to firefighting, based on the connection between fire hydrants and fire brigades.

First, the proposed method allows for the determination of the operational range of firefighting activities with respect to fire hydrants (Figure 1a) in addition to the roads through which firefighting vehicles can pass (Figure 1b).

In South Korea (according to Article 6 of the Fire Services Act), fire hydrants should be installed within a distance of $100 \mathrm{~m}$ from firefighting targets in industrial, commercial, and residential areas. In addition, the effective operation range of the fire brigade should be within a combined length of 10 extended fire hoses $(150 \mathrm{~m})$, considering the speed and accuracy of firefighting activities. The extension of firefighting hoses along a road is within a radius of approximately $100 \mathrm{~m}$ if geometrically calculated considering the curves of the fire hose [19].

Second, in this study, the widths of firefighting vehicles and roads were considered for the analysis of roads through which firefighting vehicles can pass. According to the Fire Apparatus Manufacturers' Association [20] and National Fire Agency [21], the general widths of firefighting vehicles are within the range of 1.9 to $2.5 \mathrm{~m}$. The minimum road width for the fire vehicles in previous studies conducted on fire hazards $[16,22]$ ranged from 3.0 to $4.1 \mathrm{~m}$. In this study, the minimum road widths for large/midsize vehicles and small/compact vehicles were set as 3.0 and $2.5 \mathrm{~m}$, respectively, considering the firefighting vehicle width criteria of South Korea (Table 1). 


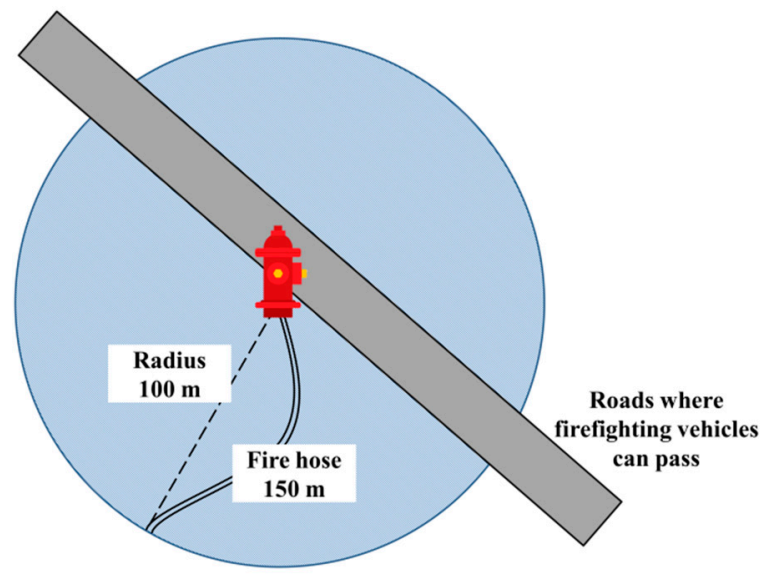

(a)

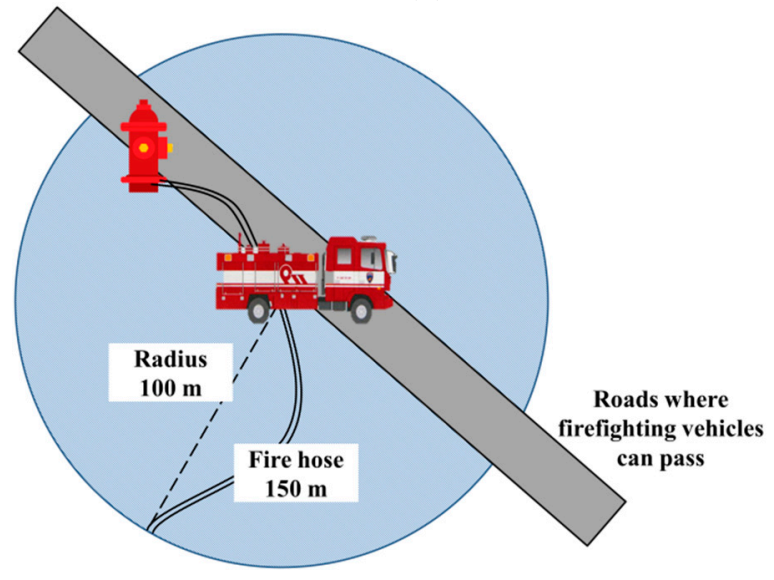

(b)

Figure 1. Operational range of firefighting activities that involve the use of fire hydrants: (a) range of firefighting activities based on fire hydrants; (b) range of firefighting activities based on fire hydrants and firefighting vehicles.

Table 1. Firefighting vehicle width criteria of South Korea [19].

\begin{tabular}{ccccc}
\hline Fire Engine & Large & Midsize & Small & Compact \\
\hline Pumper $(\mathrm{mm})$ & 2500 & 2500 & 2200 & 1900 \\
\hline Tanker $(\mathrm{mm})$ & 2500 & 2500 & 2500 & 2200 \\
\hline
\end{tabular}

Finally, water supply strategies were considered with respect to the distance between the fire hydrant and the site of the fire. Figure 2 presents the firefighting vehicle squad organisation and response strategies in South Korea. If the distance between a fire hydrant and the scene of the fire is less than $200 \mathrm{~m}$, a pumper is connected to the fire hydrant to supply water to the tanker used for firefighting activities (Figure 2a). If the distance ranges from 200 to $400 \mathrm{~m}$, a relay vehicle is positioned at the middle point and water is supplied to the tanker by a direct connection between the fire hydrant and the tanker (Figure 2b). For distances of $400 \mathrm{~m}$ and more, several vehicles receive water from nearby fire hydrants and supply it to the tanker (Figure 2c). In this study, firefighting targets and regions outside of 200 or $400 \mathrm{~m}$ from the fire hydrants were set as vulnerable areas with respect to firefighting activities, considering the direct connection between fire hydrants and the fire brigade. This was done to facilitate an uninterrupted water supply and the prevention of traffic congestion. 

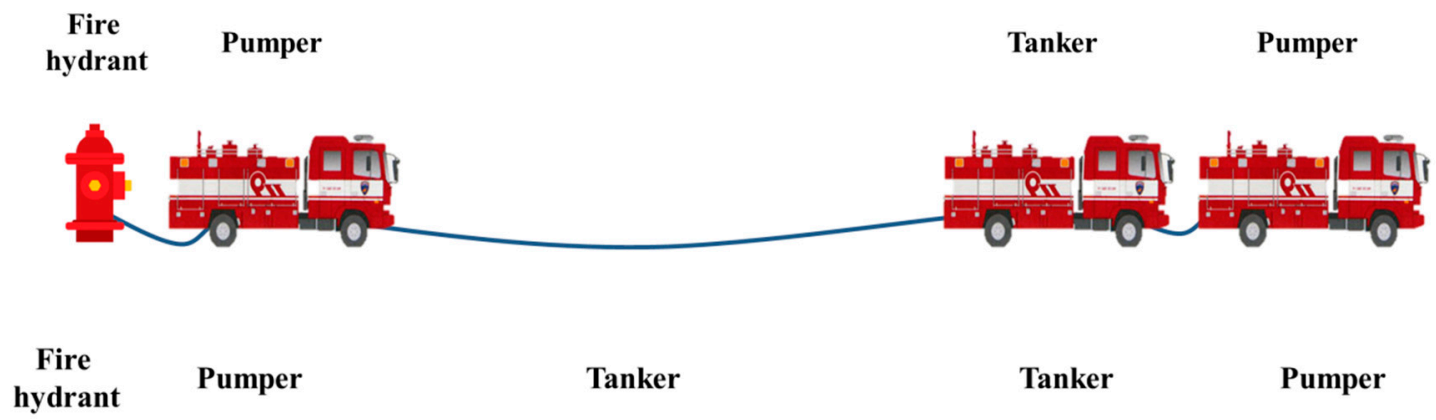

(b)

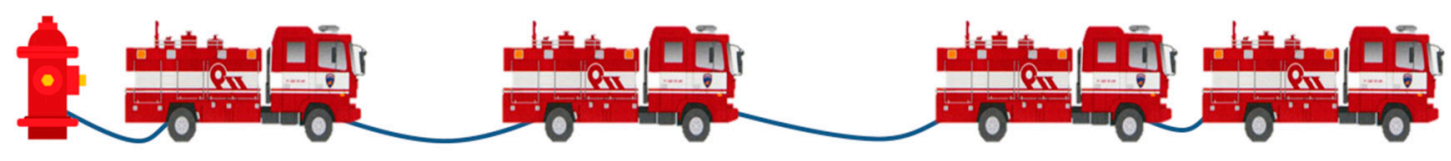

(c)

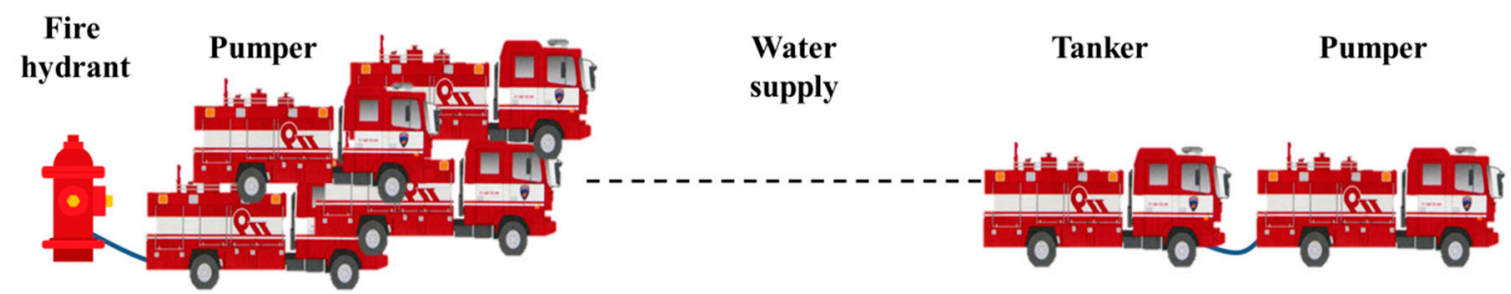

Figure 2. Water supply strategies with respect to the distance between the fire hydrant and scene of the fire (a) within 200 m; (b) between 200 and $400 \mathrm{~m}$; (c) greater than $400 \mathrm{~m}$.

To analyse the three factors, a GIS network analysis was conducted, and analysis tools such as clips and buffers were used. Figure 3 presents a flowchart of the GIS analysis.

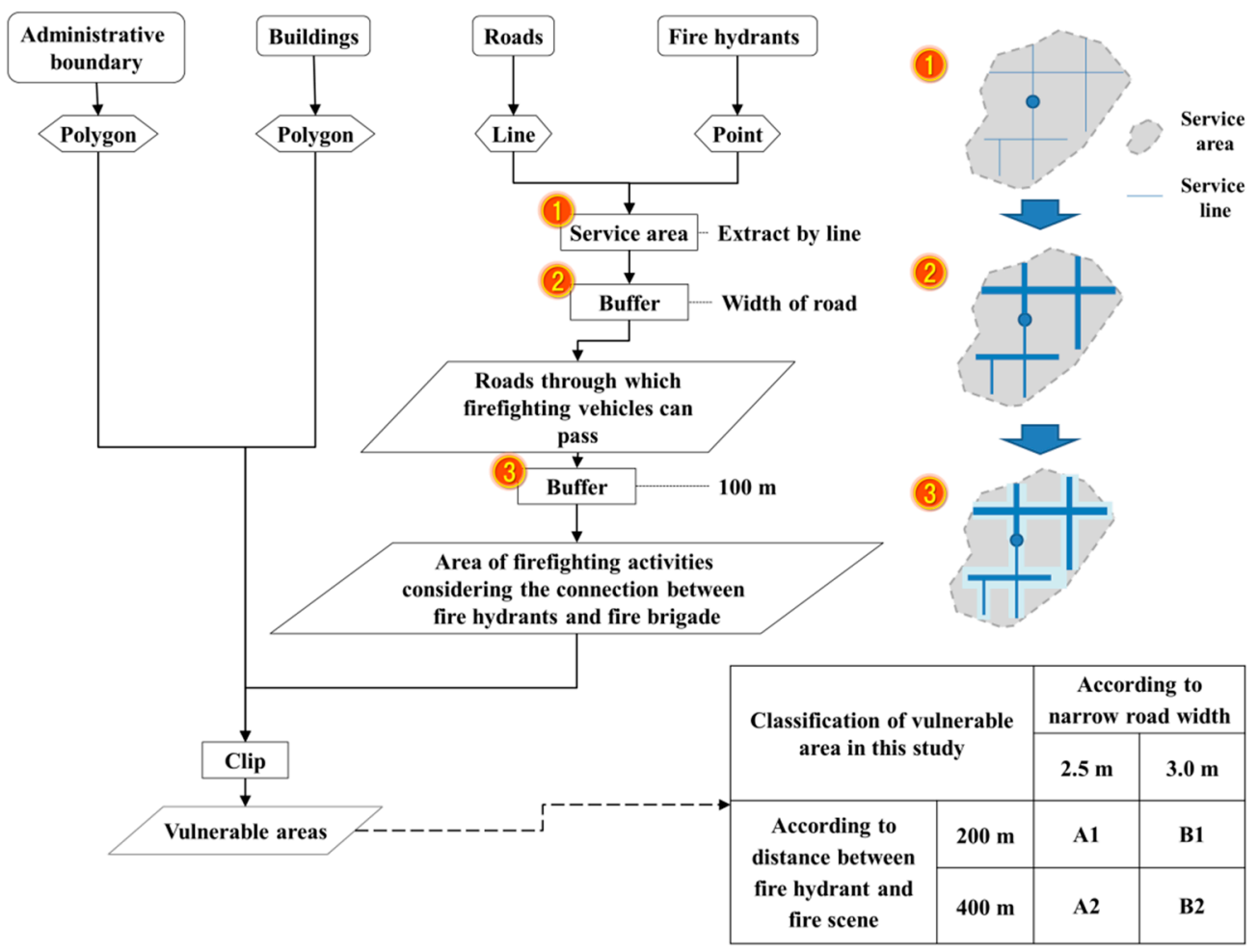

Figure 3. Flowchart of GIS analysis. 


\section{Results}

\subsection{Target Area}

The area of Buk-gu, Daegu City is $94.16 \mathrm{~km}^{2}$. There are 42,160 buildings and a population of 437,710 people in the area. There are 904 fire hydrants in this area. In total, 3865 fires occurred in the area over a period of 10 years (2007-2016). Figure 4 presents the distribution of roads and fire hydrants within the target area.

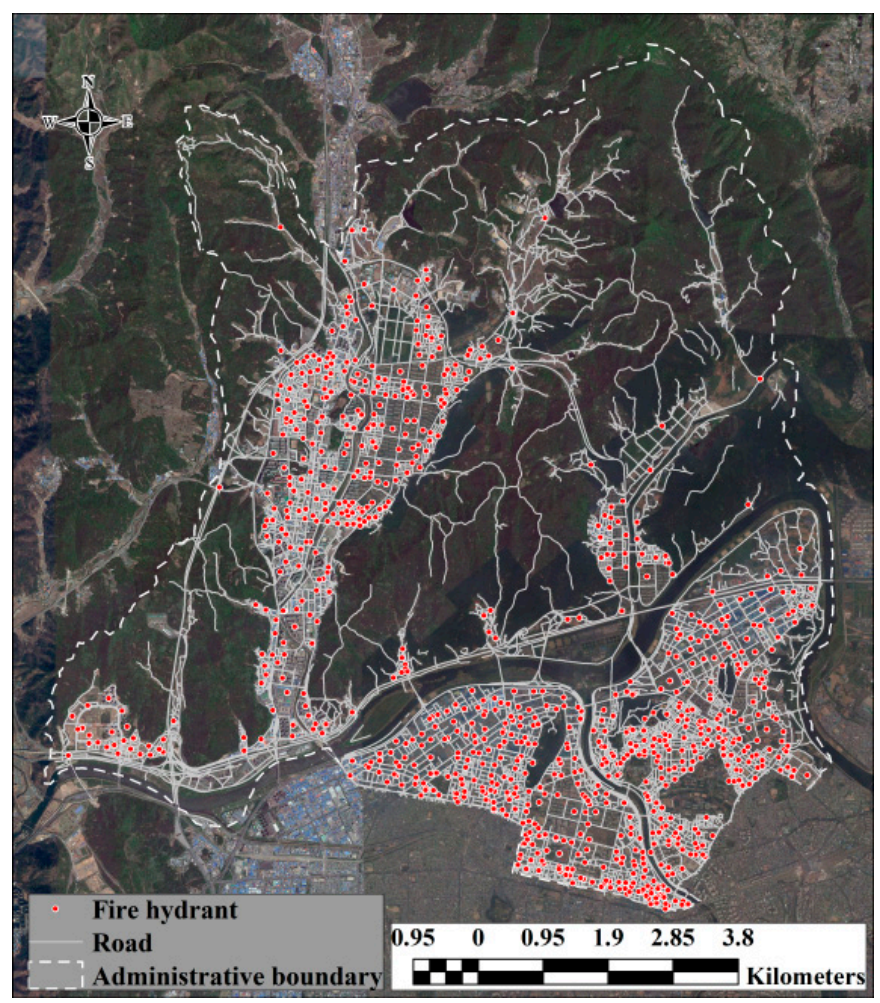

Figure 4. Distribution of roads and fire hydrants in the target area.

For the GIS analysis, the spatial data (administrative boundaries, buildings, fire hydrants, and roads) of the target area were collected, and the forms (i.e., polygons, points, and lines) of the spatial data were converted as shown in Figure 3.

\subsection{Service Area Analysis (the Regional Proximity)}

In this study, the GIS service area tool was used to analyse the regional proximity of firefighting activities. As detailed in Section 2, in the network analysis, 2.5 and $3.0 \mathrm{~m}$ were set as the thresholds of road widths for the passage of large/midsize and small/compact firefighting vehicles, respectively. Figure 5 presents the distribution of roads within the target area through which firefighting vehicles cannot pass.

Based on the water supply strategies with respect to the distance between fire hydrants and fire sites, 200 and $400 \mathrm{~m}$ were set as the reference distances, and a service area analysis was conducted. In the Arc GIS's service area analysis, the results are typically expressed in the form of polygons. However, as Figure 3 indicates, the proposed methodology is to extract the results of the service area analysis through lines. Since the goal of this study is to derive firefighting operation areas or vulnerable areas based on the connection between fire hydrants and the fire brigade, it is more appropriate to extract the results of service area analysis in the form of road network lines. Therefore, the results were extracted with respect to lines (Phase 1 in Figure 3), and road data for the operation of firefighting vehicles were obtained by plotting polygons that reflected the width of each road using the buffer tool (Phase 2 in Figure 3). To determine the operational range of firefighting activities with respect to fire hydrants and firefighting vehicles, firefighting operation areas were 
determined using the roads through which firefighting vehicles can pass (polygon) and the buffer tool $(100 \mathrm{~m})$, as shown in Figure 6.

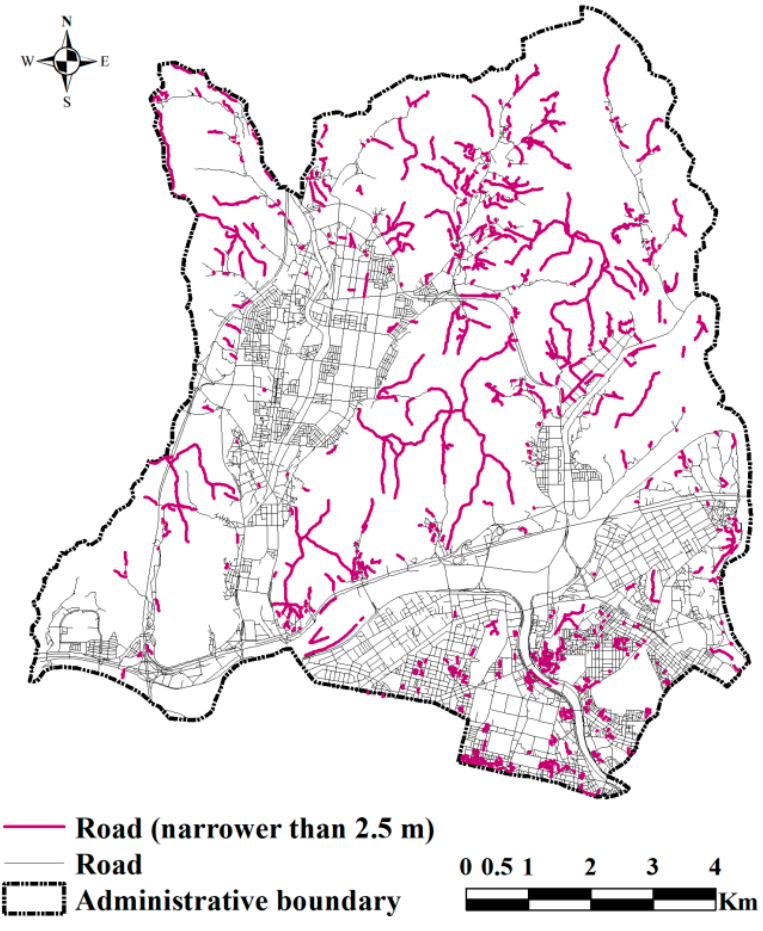

(a)

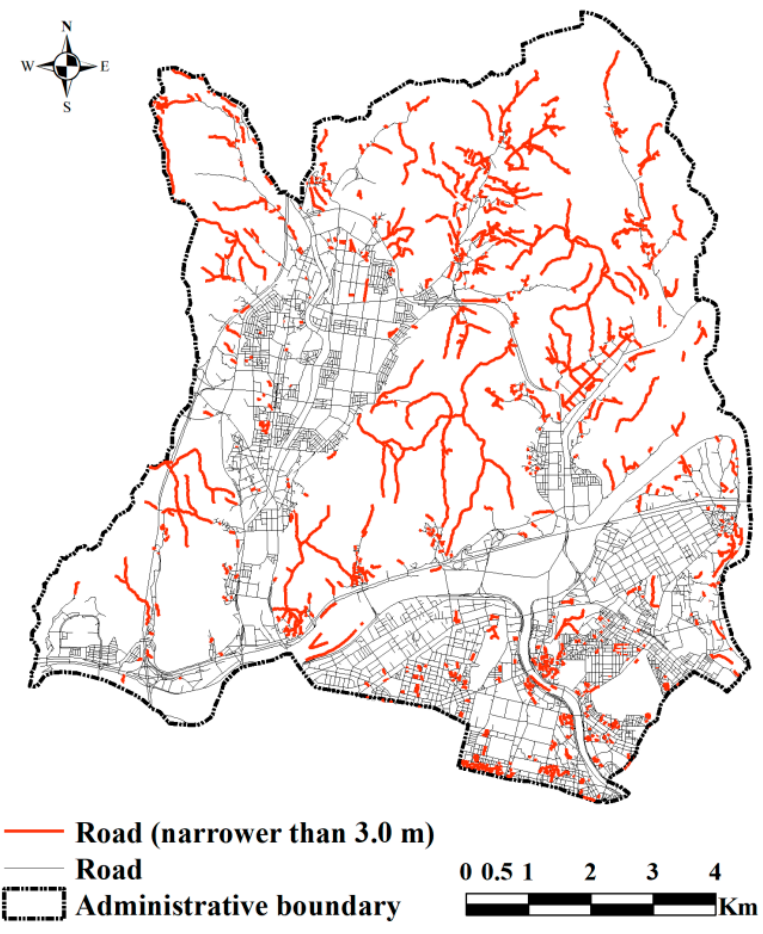

(b)

Figure 5. Distribution of roads through which firefighting vehicles cannot pass. (a) Widths less than 2.5 m; (b) widths less than $3.0 \mathrm{~m}$.

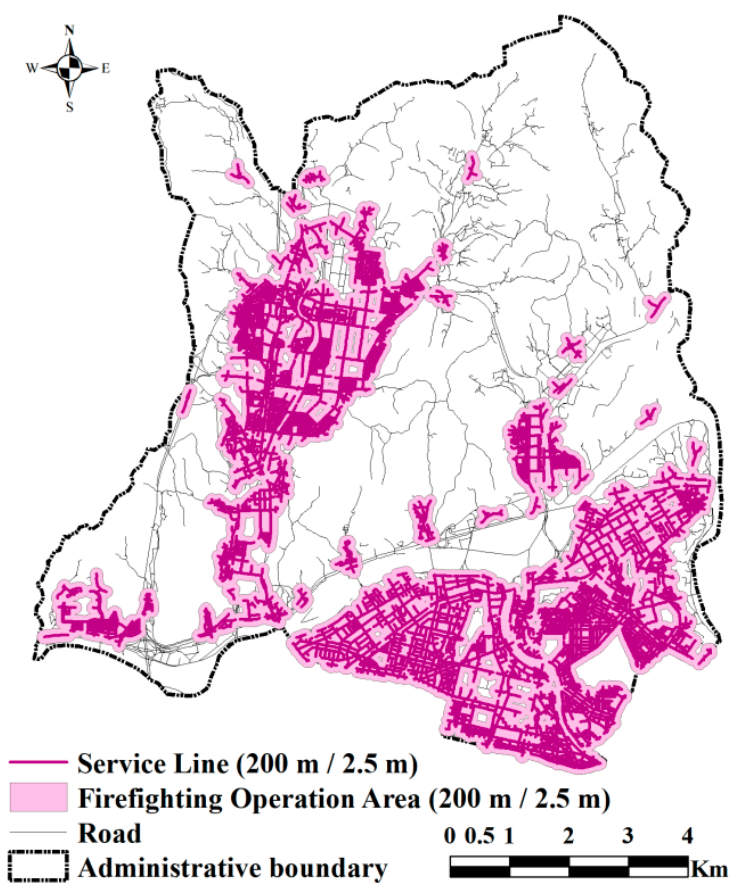

(a)

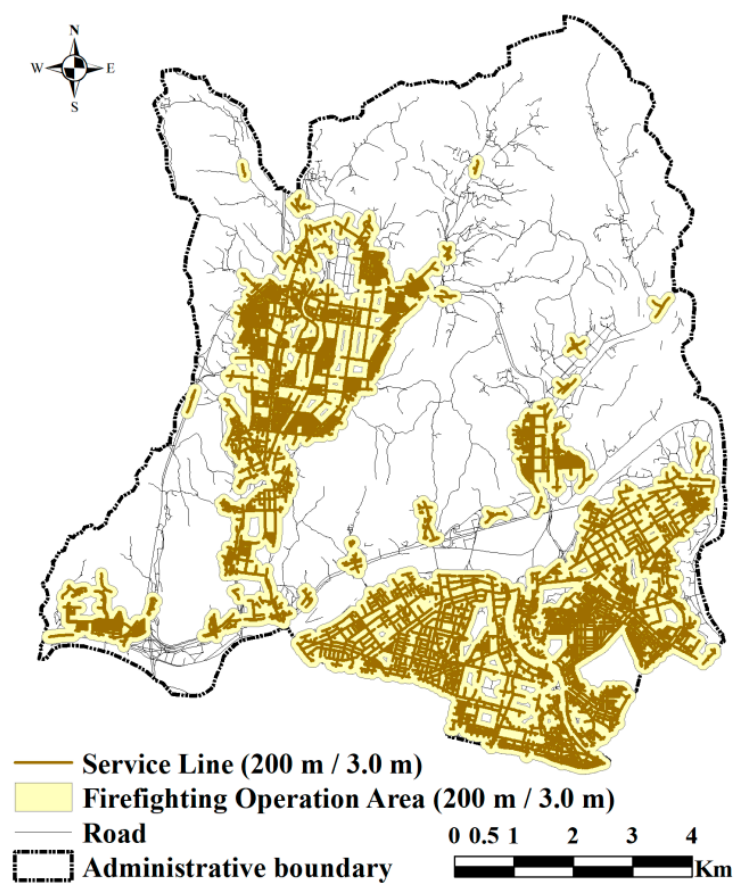

(b)

Figure 6. Cont. 


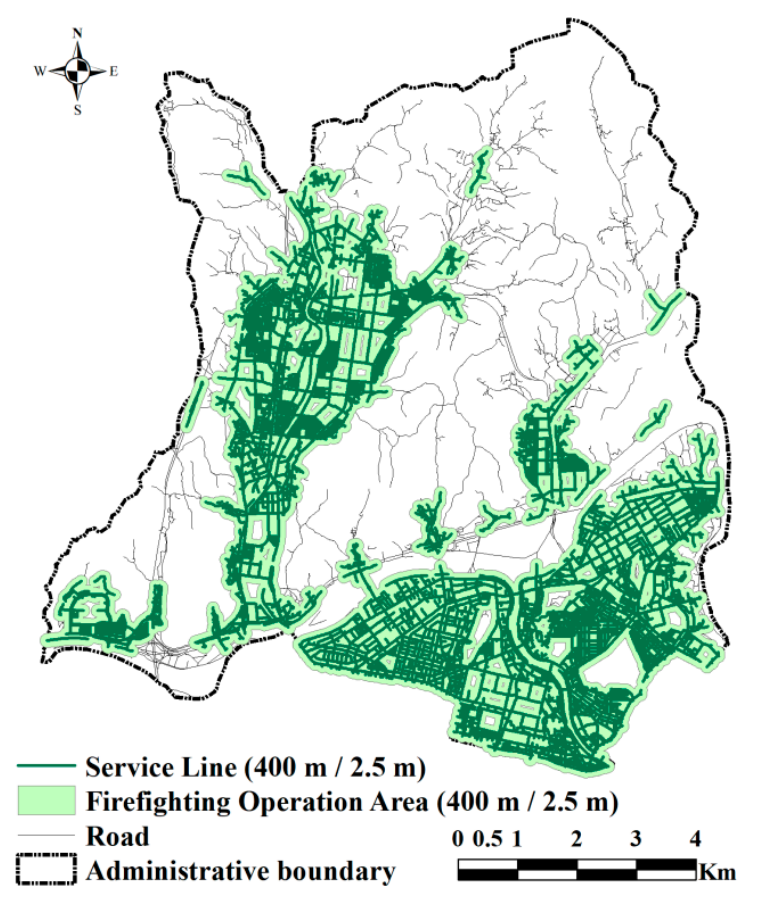

(c)

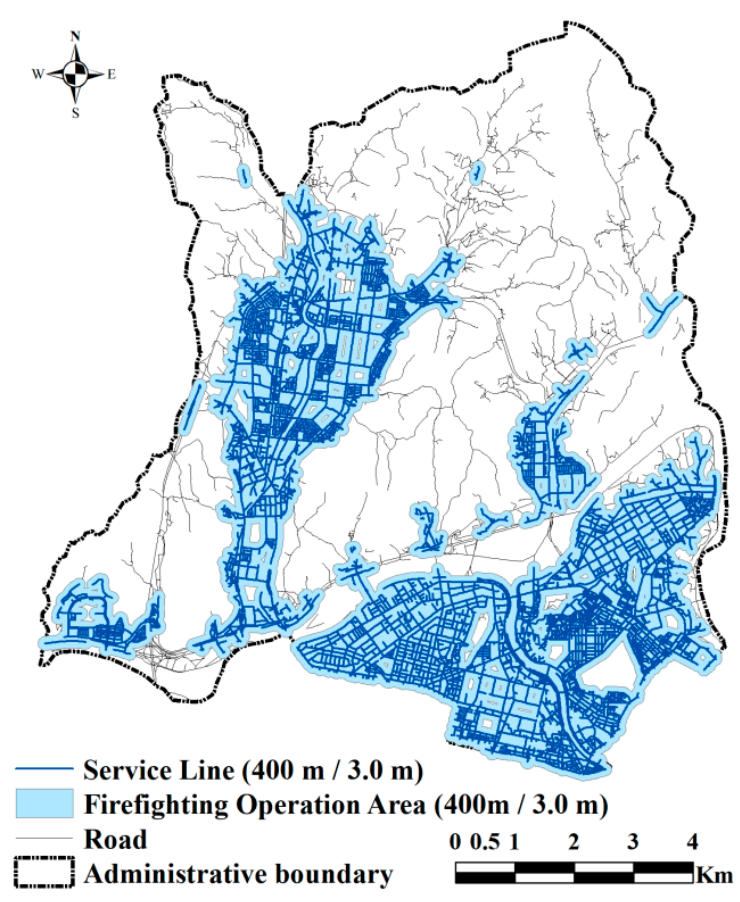

(d)

Figure 6. Analysis results of the area of firefighting operation considering the connection between the fire hydrants and fire brigade (a) within $200 \mathrm{~m}$ from fire hydrants, small vehicles are allowed to pass, and large vehicles are not allowed to pass; (b) within $200 \mathrm{~m}$ from fire hydrants, both small and large vehicles are allowed; (c) within $400 \mathrm{~m}$ from fire hydrants, small vehicles are allowed to pass, and large vehicles are not allowed to pass; (d) within $400 \mathrm{~m}$ from fire hydrants, both small and large vehicles are allowed to pass.

\subsection{Analysis of Vulnerable Areas (the Regional Availability)}

In this study, areas other than the area of firefighting operation were set as vulnerable areas considering the connection between fire hydrants and the fire brigade. Figures 7 and 8 present the analysis results for the vulnerable areas for firefighting activities with respect to fire hydrants and firefighting vehicles. Vulnerable area A1 in Figure 7 is situated at a distance of more than $200 \mathrm{~m}$ from the fire hydrants, and it represents regions wherein firefighting activities are difficult to conduct (for large and small firefighting vehicles) due to narrow roads. The area represents $64.04 \%$ of the target area, and $3.43 \%$ of the total number of buildings are located within this area. Vulnerable area B1 in Figure 7 is situated at a distance of more than $200 \mathrm{~m}$ from the fire hydrants, and it represents regions wherein firefighting activities that involve the use of large firefighting vehicles are difficult to conduct due to narrow roads (activities of small firefighting vehicles can be conducted). The area represents $64.96 \%$ of the target area, and $4.13 \%$ of the total number of buildings are located within this area. Vulnerable area A2 in Figure 7 is situated at a distance of more than $400 \mathrm{~m}$ from the fire hydrants, and it represents regions wherein firefighting activities are difficult to conduct (for small and large firefighting vehicles) due to narrow roads. The area represents $58.68 \%$ of the target area, and $2.36 \%$ of the total number of buildings are located within this area. Vulnerable area B2 in Figure 7 is situated at a distance of more than $400 \mathrm{~m}$ from the fire hydrants, and it represents regions wherein firefighting activities that involve the use of large firefighting vehicles are difficult to conduct due to narrow roads (activities of small firefighting vehicles can be conducted). The area represents $60.58 \%$ of the target area, and $3.18 \%$ of the total number of buildings are located within this area (Figure 8). 


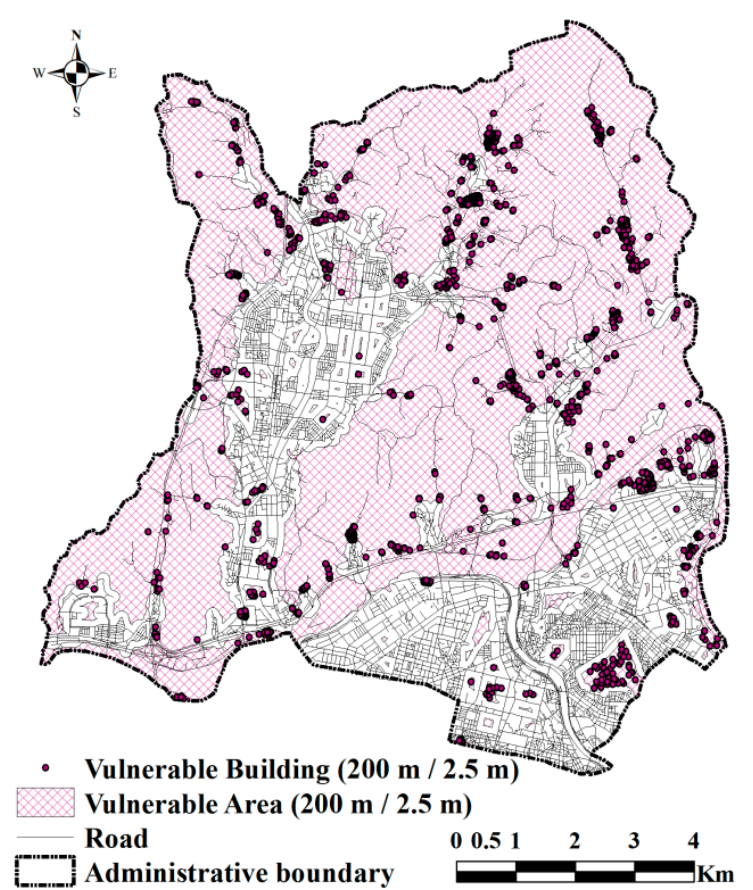

(a)

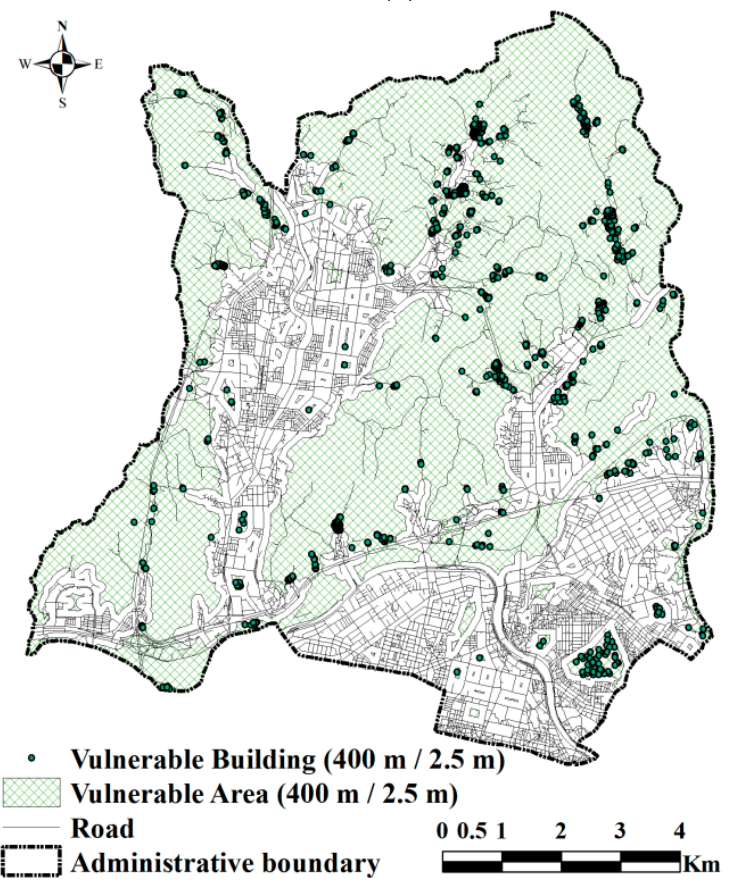

(c)

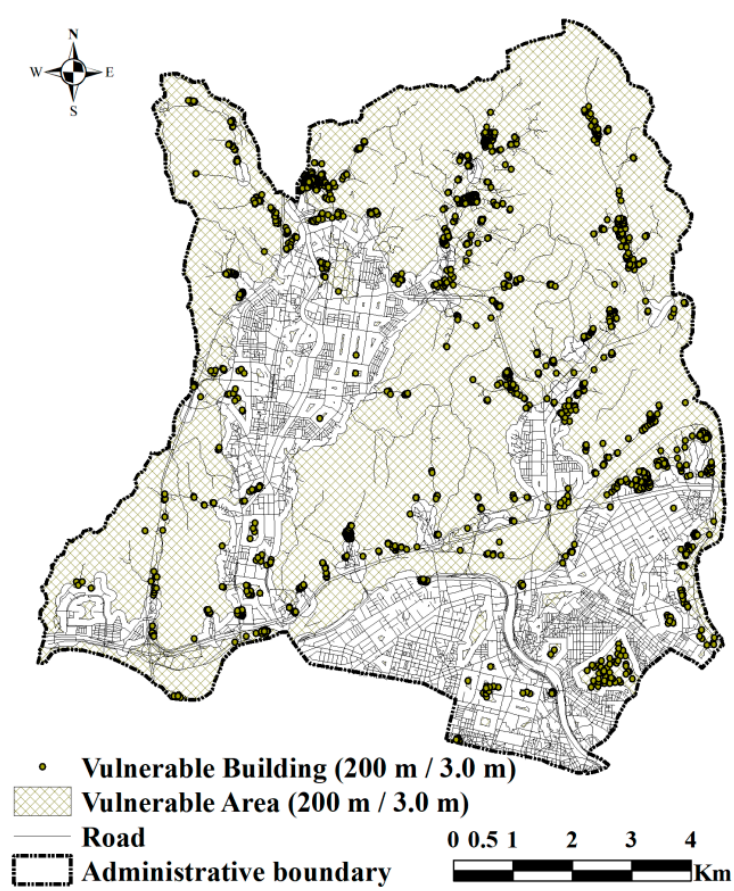

(b)

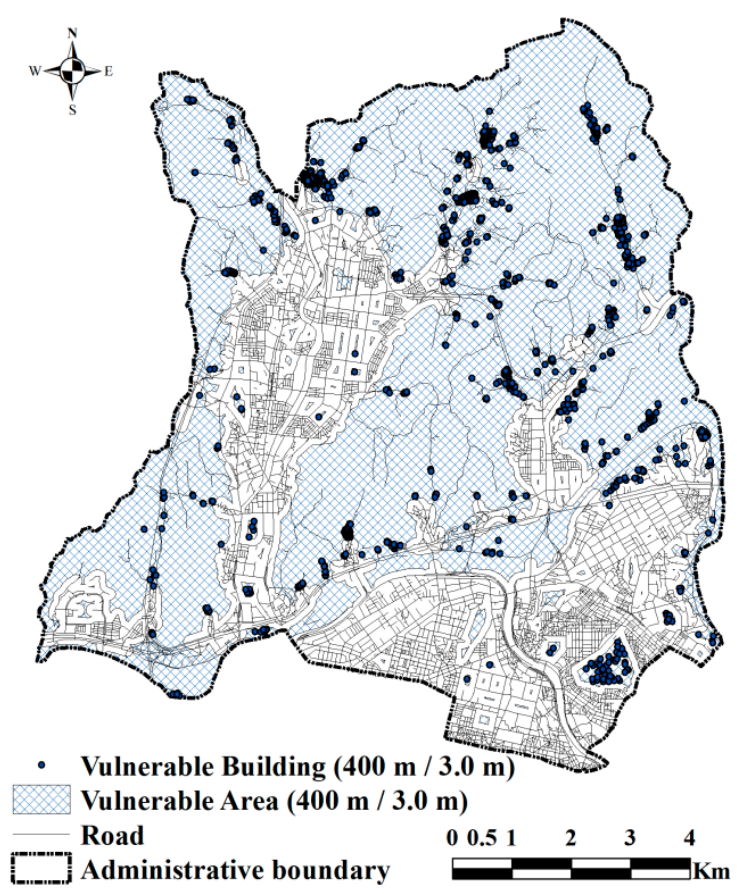

(d)

Figure 7. Analysis results of vulnerable areas for firefighting activities with respect to fire hydrants and firefighting vehicles. (a) Vulnerable area A1; (b) vulnerable area B1; (c) vulnerable area A2; (d) vulnerable area B2. 


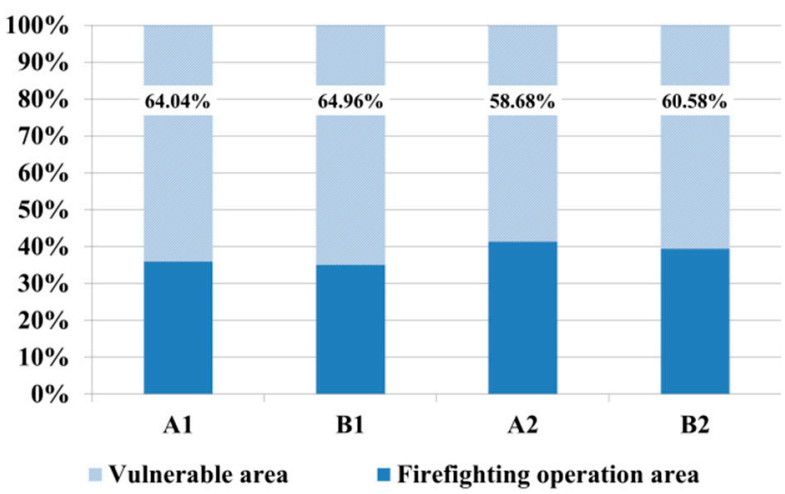

(a)

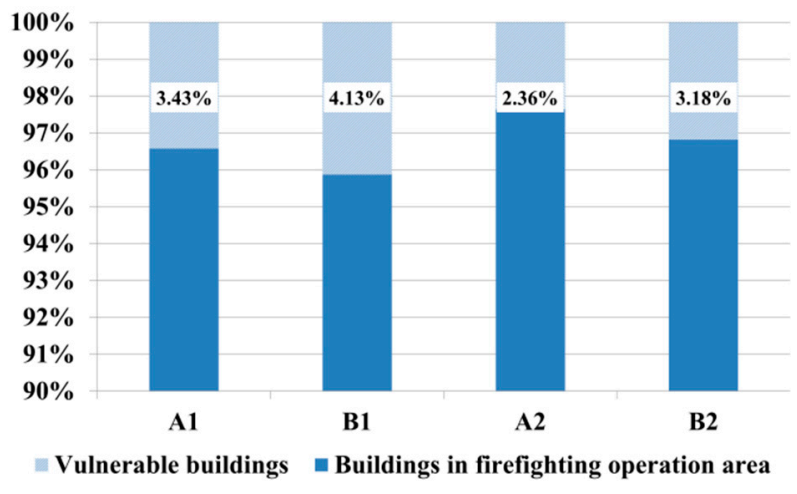

(b)

Figure 8. Analysis results of vulnerable areas for firefighting activities. (a) Area; (b) total number of buildings.

\section{Discussion}

\subsection{Proposed Method}

This study complements previous studies conducted on the accessibility to fire hydrants. Raškauskaite and Grigonis [14] analysed accessibility to fire hydrants using the GIS buffer tool; however, the research was limited, and the operational range of actual firefighting activities that involve the use of fire hydrants could not be determined. Therefore, in this study, the range of firefighting activities was determined based on the connection between firefighting vehicles and fire hydrants. The proposed method can be used to accurately predict the range of actual firefighting activities and determine vulnerable areas because it considers the connection between firefighting vehicles and fire hydrants.

"The safety and sustainability of the territory is ensured by inter alia safety planning, including spatial planning" [23]. This study can be used in spatial planning for better urban fire response or reducing vulnerable areas in relation to urban safety and sustainability. For example, the proposed methodology can be developed to ensure accessibility for firefighting activities (i.e., prioritisation of the expansion of narrow alleys, selection of fire hydrant locations, and the establishment of firefighting mobilisation plans) because it considers the fire brigade activities, fire hydrant location, and road status. A method to determine the priorities with respect to the expansion of narrow alleys, e.g., [16] was recently proposed to minimise the response time of firefighting operations and improve accessibility to scenes of fire. In addition, selection methods for fire hydrant locations, e.g., [24] were presented to facilitate firefighting operations in population-dense communities that are difficult to access. However, in previous studies, the fire hydrant locations and the widths of firefighting vehicles and roads were not comprehensively considered. The proposed methodology can complement the previous studies conducted on accessibility with respect to firefighting activities and can be used to establish strategies for an improved response to urban fires. In particular, the types and combinations of vehicles to be dispatched can be determined in advance, considering the characteristics (road width and distance to fire hydrants) of the scene of the fire, as shown in Figure 9. Figure 9a presents the areas derived by the exclusion of vulnerable area A1 from vulnerable area B1, which represent regions wherein only small vehicles can be used in the areas situated within $200 \mathrm{~m}$ of the fire hydrants. Figure $9 \mathrm{~b}$ presents the areas derived by the exclusion of vulnerable area A2 from vulnerable area $B 2$, which represent regions wherein only small vehicles can be used in the areas located within $400 \mathrm{~m}$ of the fire hydrants. 


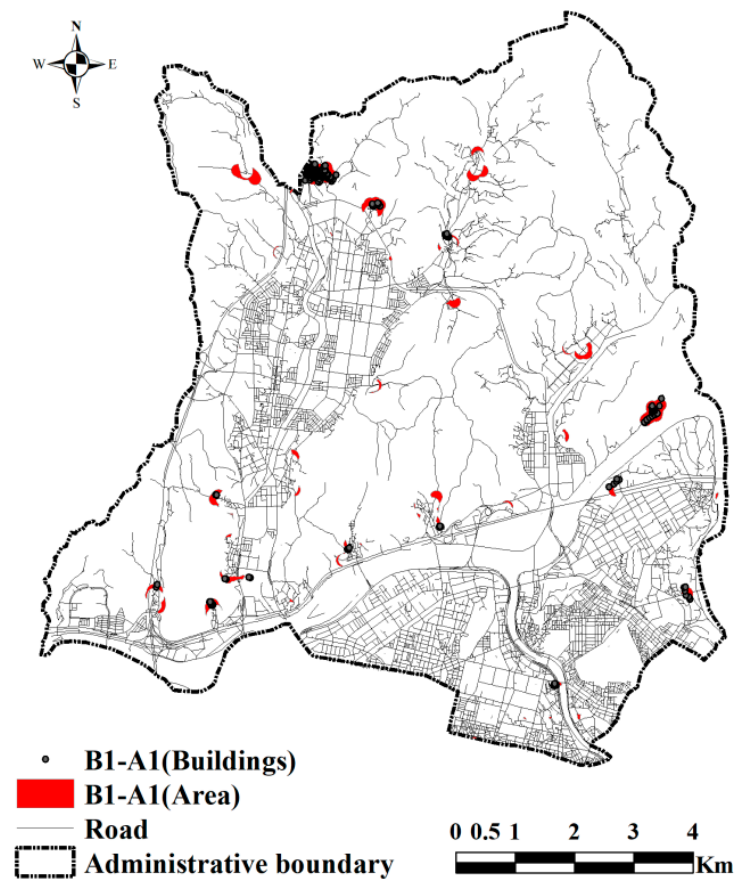

(a)

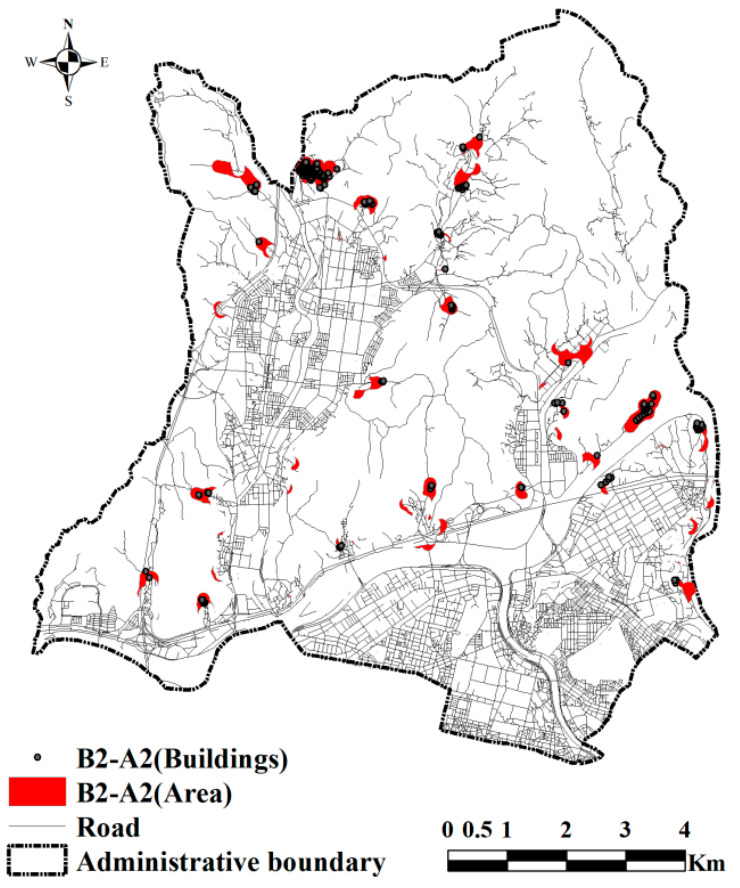

(b)

Figure 9. Analysis results of vulnerable areas for firefighting activities with respect to the types and combinations of vehicles to be dispatched. (a) Vulnerable area B1—vulnerable area A1, 279 locations; (b) vulnerable area b2—vulnerable area A2, 384 locations.

In addition, this approach can contribute to the determination of installation locations for fire-response equipment, such as emergency fire-extinguishing devices in areas with narrow roads, by the determination of vulnerable areas for firefighting activities. For example, facilities (foldable water pipes and hose reels) can be installed in vulnerable areas wherein fire hoses are connected to fire hydrants, thus allowing residents to suppress the fire at an early stage prior to the arrival of the fire brigade.

\subsection{Limitations and Scope of Future Research}

This study was conducted with a focus on the connection between fire hydrants and fire brigades within the context of firefighting operations. In particular, the connection between fire hydrants and fire brigades in firefighting operations was assumed; however, many fire accidents can be suppressed without the use of fire hydrants [25]. According to [25], $75 \%$ of the fire accidents in Johannesburg, South Africa could be suppressed without the use of fire hydrants. Although fire hydrants are critical to ensure a sufficient supply of water, it is necessary to comprehensively consider the characteristics (i.e., distribution, structure, and material of firefighting targets) and fire status (i.e., the number of fire accidents and amount of water used) of a city to establish cost-effective firefighting strategies for the entire city. Moreover, natural water sources can be used for firefighting activities [16]. Therefore, it is necessary to consider natural water sources (i.e., ponds and rivers) and fire hydrants for the evaluation of the regional fire risk or the capacity of fire stations. In addition, the widths of pumpers and tankers were considered in this study; however, special-purpose vehicles required for firefighting activities in high-rise buildings, such as ladder trucks, were not considered. In particular, a minimum width of $6 \mathrm{~m}$ is required to fix ladder trucks to the ground.

In this study, a comprehensive vulnerability analysis of firefighting activities was not conducted. Ronan and Teeuw [26] conducted a vulnerability analysis considering the flow rates of fire hydrants and building types. Liu et al. [27] calculated the travel times, distances, and paths between the fire stations and firefighting demand points with respect 
to the real-time traffic conditions using the web service application programming interface (API) of an online map. In this study, the fire hydrant location was considered, and the flow rate was not. In addition, the building types, actual traffic conditions, and fire damage data were not considered for the analysis. In future research, the flow rate of fire hydrants, actual fire damage data, building data, and road data should be comprehensively considered for the vulnerability analysis of firefighting activities, including the connection between fire hydrants and firefighting vehicles.

\section{Conclusions}

In this study, a method was developed to determine the operational range of firefighting activities based on the distribution of fire hydrants and roads through which firefighting vehicles can pass and to determine the vulnerable areas based on this range. Hence, a novel GIS-based analysis method is proposed, which considers the widths of roads and firefighting vehicles, in addition to the water supply strategies, with respect to the distance between fire hydrants and the fire sites. The proposed method, which considers the connection between fire hydrants and the fire brigade in firefighting operations, is a comprehensive analysis technique for evaluating accessibility to fire hydrants. Moreover, it can contribute to improved operational firefighting strategies.

Author Contributions: All authors contributed extensively to the work. Y.H.L. and J.S.L. conceptualised and designed the study. Y.H.L., J.S.L. and M.S.K. produced the data required to apply the methodology to the study area and conducted the analysis, validation, and writing and preparing the original draft. Y.H.L. and M.S.K. analysed the results, completed the manuscript, wrote the review, and assisted in editing. J.S.L. supervised the project and acquired the funding. All authors have read and agreed to the published version of the manuscript.

Funding: This research was funded by the National Research Foundation of Korea (NRF) grant number [NRF-2018R1D1A1B07049769].

Acknowledgments: This work was supported by the National Research Foundation of Korea (NRF) grant funded by the Korean government (NRF-2018R1D1A1B07049769).

Conflicts of Interest: The authors have no conflicts of interest to declare.

\section{References}

1. Rahardjo, H.A.; Prihanton, M. The most critical issues and challenges of fire safety for building sustainability in Jakarta. J. Build. Eng. 2020, 29, 101133. [CrossRef]

2. Zhu, L.; Tong, H.; Lou, L.; Xiong, Y. A state monitoring method of fire water supply system based on hydraulic pressure mean value. In Proceedings of the 2017 13th IEEE International Conference on Electronic Measurement \& Instruments (ICEMI) IEEE, Yangzhou, China, 20-23 October 2017; pp. 74-79.

3. Kahanji, C.; Walls, R.S.; Cicione, A. Fire spread analysis for the 2017 Imizamo Yethu informal settlement conflagration in South Africa. Int. J. Disaster Risk Reduct. 2019, 39, 101146. [CrossRef]

4. Stevens, S.; Gibson, L.; Rush, D. Conceptualising a GIS-based risk quantification framework for fire spread in informal settlements: A Cape Town case study. Int. J. Disaster Risk Reduct. 2020, 50, 101736. [CrossRef]

5. Chen, M.; Wang, K.; Dong, X.; Li, H. Emergency rescue capability evaluation on urban fire stations in China. Process. Saf. Environ. Prot. 2020, 135, 59-69. [CrossRef]

6. Boye, C.B.; Abubakar, T. Application of Geographic Information System in Emergency Service Delivery-A Case of Ghana National Fire Service. Ghana J. Technol. 2019, 3, 65-72.

7. Wei, Y.-Y.; Zhang, J.-Y.; Wang, J. Research on Building Fire Risk Fast Assessment Method Based on Fuzzy comprehensive evaluation and SVM. Procedia Eng. 2018, 211, 1141-1150. [CrossRef]

8. Du, F.; Okazaki, K.; Ochiai, C. Disaster coping capacity of a fire-prone historical dong village in China: A case study in Dali Village, Guizhou. Int. J. Disaster Risk Reduct. 2017, 21, 85-98. [CrossRef]

9. Shahparvari, S.; Fadaki, M.; Chhetri, P. Spatial accessibility of fire stations for enhancing operational response in Melbourne. Fire Saf. J. 2020, 117, 103149. [CrossRef]

10. Kocatepe, A.; Ulak, M.B.; Kakareko, G.; Ozguven, E.E.; Jung, S.; Arghandeh, R. Measuring the accessibility of critical facilities in the presence of hurricane-related roadway closures and an approach for predicting future roadway disruptions. Nat. Hazards 2019, 95, 615-635. [CrossRef]

11. Oppong, J.R.; Boakye, K.; Edziyie, R.; Owusu, A.Y.; Tiwari, C. Emergency fire response in Ghana: The case of fire stations in Kumasi. Afr. Geogr. Rev. 2016, 36, 253-261. [CrossRef] 
12. Nisanci, R. GIS based fire analysis and production of fire-risk maps: The Trabzon experience. Sci. Res. Essays 2010, 5, 970-977.

13. Xia, Z.; Li, H.; Chen, Y.; Yu, W. Integrating Spatial and Non-Spatial Dimensions to Measure Urban Fire Service Access. ISPRS Int. J. Geo-Inf. 2019, 8, 138. [CrossRef]

14. Raškauskaitè, R.; Grigonis, V. An Approach for the Analysis of the Accessibility of Fire Hydrants in Urban Territories. ISPRS Int. J. Geo-Inf. 2019, 8, 587. [CrossRef]

15. Medyńska-Gulij, B. Cartographic visualization of firehydrants accessibility for the purpose of decision making. Geod. Cartogr. 2013, 62, 183-198. [CrossRef]

16. Chen, P.A.; Wu, H.T.; Hsu, Y.T. Widening Narrow Alleys to Enhance Response Efficiency for Fire Emergency from the Perspective of Urban Roadway Network Analysis. J. East. Asia Soc. Transp. Stud. 2019, 13, 2598-2613. [CrossRef]

17. Yoshihara, T.; Tanaka, T.; Inachi, S.; Saito, H. Factors influencing street use frequency and evaluation of street image in densely built-up areas: A case study in Shinyo neighborhood, Nagata Ward, Kobe. J. Asian Arch. Build. Eng. 2020, 1-19. [CrossRef]

18. Skondras, N.A.; Tsesmelis, D.E.; Vasilakou, C.G.; Karavitis, C.A. Resilience-Vulnerability Analysis: A Decision-Making Framework for Systems Assessment. Sustainability 2020, 12, 9306. [CrossRef]

19. Seoul Metropolitan Fire and Disaster Headquarters. Firefighting Tactics in Newcomer Training Program. 2019. (In Korean). Available online: https: / / fire.seoul.go.kr/upload/board/28332_15953747398129816.pdf (accessed on 2 September 2020).

20. Fire Apparatus Manufacturers' Association. Emergency Vehicle Size and Weight Guide. Available online: https://www.fama. org/wp-content/uploads/2017/12/1514564588_5a466bec19c41.pdf (accessed on 31 August 2020).

21. National Fire Agency. Fire Equipment Information. (In Korean). Available online: https://www.nfa.go.kr/nfa/ releaseinformation $/ 0010 / 0001 /$ ?boardId=bbs_0000000000000566\&mode=view\&cntId=25\&category=\&pageIdx=2\&searchCondition= all\&searchKeyword (accessed on 31 August 2020).

22. Lee, C.-A.; Sung, Y.-C.; Lin, Y.-S.; Hsiao, G.L.-K. Evaluating the severity of building fires with the analytical hierarchy process, big data analysis, and remote sensing. Nat. Hazards 2020, 103, 1843-1856. [CrossRef]

23. Pokorny, J.; Machalova, B.; Slivkova, S.; Brumarova, L.; Vlcek, V. Planning of Safety of Cities and Territory from the Point of View of Population Protection in the Czech Republic. Sustainability 2020, 12, 9487. [CrossRef]

24. Okon, I.; Njoku, C.G. The Location of Fire Hydrants and Implications to Fire Disaster Management in Calabar, Cross Riv-er State, Nigeria. IOSR J. Humanit. Soc. Sci. 2018, 23, 42-55. [CrossRef]

25. Mac Bean, C.; Ilemobade, A. An evaluation of the primary South African standard and guideline for the provision of water for firefighting. Water SA 2019, 45, 691-699. [CrossRef]

26. Ronan, T.; Teeuw, R.M. London's burning: Integrating water flow rates and building types into fire risk maps. Int. J. Emerg. Serv. 2016, 5, 34-51. [CrossRef]

27. Liu, D.; Xu, Z.; Wang, Z.; Zhou, Y.; Fan, C. Estimation of effective coverage rate of fire station services based on real-time travel times. Fire Saf. J. 2020, 103021. [CrossRef] 